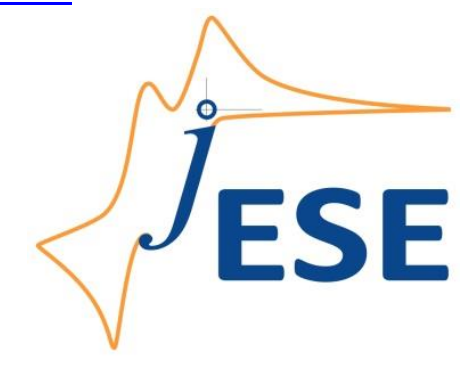

Open Access : : ISSN 1847-9286

www.jESE-online.org

Original scientific paper

\title{
Modelling the effect of anode particle radius and anode reaction rate constant on capacity fading of Li-ion batteries
}

\author{
Vikalp Jha and Balaji Krishnamurthy \\ Department of Chemical Engineering, BITS Pilani, Hyderabad 500078, India \\ Corresponding author: $₫$ balaji@hyderabad.bits-pilani.ac.in
}

Received: October 21, 2021; Accepted: November 26, 2021; Published: December 6, 2021

\begin{abstract}
This paper investigates the effect of anode particle radius and anode reaction rate constant on the capacity fading of lithium-ion batteries. It is observed through simulation results that capacity fade will be lower when the anode particle size is smaller. Simulation results also show that when reaction rate constant is highest, the capacity loss is the lowest of lithiumion battery. The potential drop across the SEI layer (solid electrolyte interphase) is studied as a function of the anode particle radius and anode reaction rate constant. Modelling results are compared with experimental data and found to compare well.
\end{abstract}

\section{Keywords}

SEl; potential drop; side reaction; discharge

\section{Introduction}

Side reactions can cause various adverse effects leading to capacity fading in lithium-ion batteries. The aging of Li-ion batteries usually occurs due to various parameters and electrochemical reactions, and capacity loss varies between all stages during a charge-discharge load cycle, depending on various parameters such as cell voltage, electrolyte concentration, temperature, and cell current. This work shows the model for aging and capacity loss in the anode of a Li-ion battery, where the formation of a thin film of solid-electrolyte-interface (SEI) shows an adverse capacity loss of cyclable lithium. Capacity fading in a lithium-ion battery has been studied under various load conditions.

Haran et al. [1] studied the effect of various temperatures during various cycles in the capacity fading of $18650 \mathrm{Li}$-ion cells. It is observed that with an increase in temperature of Li-ion batteries, capacity fading is increased. It is observed that at temperatures higher than $55^{\circ} \mathrm{C}$, the cell ceases to operate after 500 cycles due to ongoing SEI film formation over the anode surface. Han et al. [2] studied the cycle life of commercial Li-ion batteries with LTO anodes in electric vehicles. The author also found that at $55^{\circ} \mathrm{C}$, the capacity fading in the battery is more than lower operating temperature Lithium-ion battery. Liaw et al. [3] studied the correlation of Arrhenius behavior in power and capacity loss with cell impedance and heat generation at different temperatures and state of charge 
in 18650 cylindrical Li-ion cells. It is observed that degradation in power and capacity fade seems to relate to impedance increase in the cell with the activation energy of cell at different temperatures. Ramadesigan et al. [4] studied the effect of the solid-phase diffusion coefficient and side reaction rate constant in the anode, cathode, and electrolyte as a function of cycling with various reformulated models. Colclasure et al. [5] studied various detailed chemistries and transport for SEI films on Li-ion batteries with various states of charge (SOC) at different cycles. The author states that SEI film grows with time according to net production rate from heterogeneous chemistry on SEI film surface because electric-potential and concentration profiles in the SEI layer are functions of the intercalation fraction [5].

Pinson and Bazant [6] also studied the formation of SEI layer in rechargeable batteries with capacity loss, aging, and lifetime prediction in Li-ion batteries. Various models are studied at different temperatures and C-rates to study SEI layer formation and capacity fading of Li-ion batteries. The authors postulate that capacity fading depends on time, not on the number of cycles. The temperature dependence of the diffusivity of the limiting reacting species through SEI can be modelled using an Arrhenius dependence. Ziv et al. [7] examined electrochemical performance and capacity loss of half and full Li-ion batteries with several cathode materials experimentally. The authors stated that the loss of lithium ions due to side reactions is the main reason for the capacity fading of Li-ion batteries. Liu et al. [8] studied a thermal-electrochemical model for SEI formation in $\mathrm{Li}$-ion batteries during load cycles. The authors state that the growth of SEI film is very sensitive to the diffusion process and side reaction rate. It is also found that SEI film grows at a higher rate during charging than during the discharge cycle. Guo et al. [9] also studied the capacity fading of Li-ion batteries with different experiments. The authors stated that capacity fading occurred due to several reasons, including discharge rate, number of cycles, and battery type.

Ramesh et al. $[10,11]$ developed a mathematical model to study capacity loss in Li-ion batteries due to temperature, formation, and dissolution rate constants of the SEI layer. The author also developed an empirical model to study capacity fading in Li-ion batteries under different temperatures. Xu et al. [12] also studied electrode side reactions, capacity loss and mechanical degradation of Li-ion batteries through experimental observations. The author states that during load cycles for higher reaction rates, columbic efficiency is lower, but capacity fading is also lower. Shirazi et al. [13] studied the effect of composite electrode's particle size effect on electrochemical and heat generation of $\mathrm{Li}$-ion batteries. The author states that for smaller particle size, the thermal characteristics of the battery is improved in comparison to larger particle size [13]. Singhvi et al. [14] developed a mathematical model to observe the effect of acid attack on capacity fading in Li-ion batteries. The author considers SEI formation due to the transport and reaction of solvent species.

Cheng et al. [15] developed a mechanism for capacity loss of 18650 cylindrical Li-ion battery cells. The author postulates that the capacity loss of Li-ion batteries can be explained by continuous SEI layer formation over the surface of anode and side reactions. Side reaction products deposit on a separator and reduce its porosity, leading to capacity fading. Tomaszewska et al. [16] reviewed various research on fast charging of Li-ion batteries. It was observed that for fast charging, ratelimiting processes are beneficial to reduce battery degradation and increase in cycle life.

Meanwhile, Li plating, the structure of Li deposits, and temperature distribution during cycling lead to the degradation of Li-ion batteries. Gantenbein et al. [17] studied the capacity loss of Li-ion batteries over different SOC ranges. The author states that capacity fading originates from active electrodes and active lithium loss. Lee et al. [18] also studied the loss of cyclable Li on the performance degradation of Li-ion batteries. The author stated that the discharge behavior of the 
cell had a strong dependence on discharge C-rate and loss of cyclable lithium. Khaleghi Rahiman et al. [19] developed a mathematical model to study cell life with various parameters. The author studied capacity loss and SEI formation in Li-ion batteries at different temperatures at different SOCs. The author postulates that cathode side reactions are accelerated at higher SOCs and temperatures. In our model, we compare the effect of anode particle radius and anode reaction rate constant on the capacity fading of a lithium-ion battery.

\section{Model development}

A 1D model of a Li-ion battery interface is created, as shown in Figure 1. The components of a Liion battery are the negative electrode, positive electrode, and separator. Graphite electrode $\left(\mathrm{Li}_{x} \mathrm{C}_{6}\right)$ $\mathrm{MCMB}$ is used for negative electrode material, NCA electrode ( $\mathrm{LiNi}_{0.8} \mathrm{Co}_{0.15} \mathrm{Al}_{0.05} \mathrm{O}_{2}$ ) is used for positive electrode material and $\mathrm{LiPF}_{6}(3: 7$ in EC: EMC) is used as a liquid electrolyte.

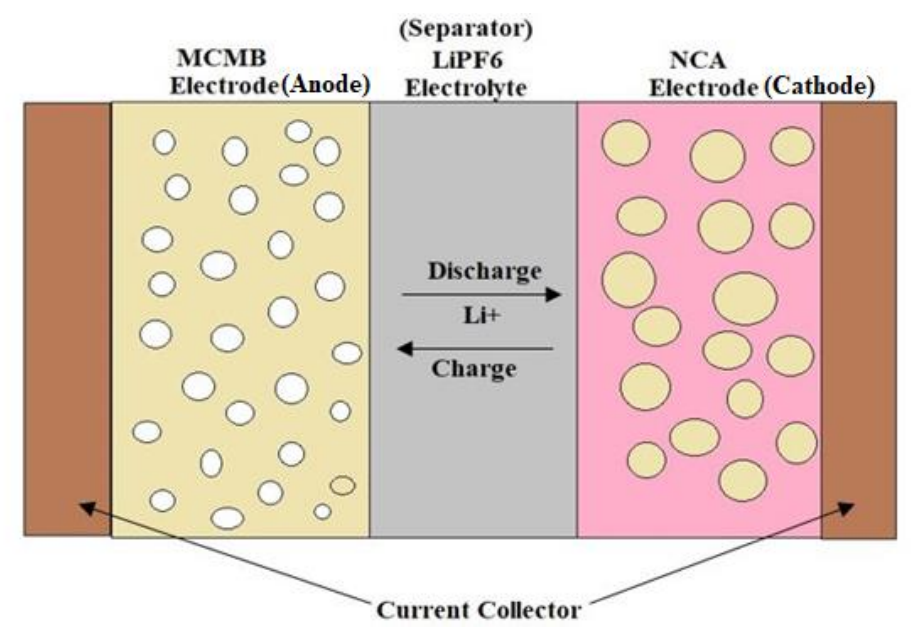

Figure 1. Schematic of the $1 D$ electrochemical model of Li-ion battery

\section{Model equations}

The model equations analyze the current equilibrium in the electrolyte and electrodes, the mass balance for the lithium and electrolyte in Li-ion batteries. The Li-ion battery physics at interface analyses five dependent variables:

a) $\phi_{s}$ - the electric potential,

b) $\phi_{\mathrm{e}}$ - the electrolyte potential,

c) $\Delta \phi_{\text {SEI }}$ - the potential losses due to solid-electrolyte interface (SEI),

d) $c_{\mathrm{Li}}$ - the concentration of lithium in the electrode particles

e) $c_{\mathrm{e}}$ - the electrolyte salt concentration.

The domain equations in the electrolyte are the conservation of current and the mass balance for the salt according to the following [20]:

$$
\begin{aligned}
& i_{\text {sum }}+Q_{\mathrm{e}}=\nabla\left(-\sigma_{\mathrm{e}} \nabla \phi_{\mathrm{e}}+\left(\frac{2 \sigma_{\mathrm{e}, \mathrm{eff}} R T}{F}\right)\left(1+\frac{\partial \ln f}{\partial \ln c_{\mathrm{e}}}\right)\left(1+t_{+}\right) \nabla \ln c_{\mathrm{e}}\right) \\
& \varepsilon_{\mathrm{e}} \frac{\partial c_{\mathrm{e}}}{\partial t}+\nabla\left(-\varepsilon_{\mathrm{e}} D_{\mathrm{e}} \nabla c_{\mathrm{e}}\right)=R_{\mathrm{e}}-\left(\frac{i_{\text {sum }}+Q_{e}}{F}\right) t_{+}
\end{aligned}
$$

where $\sigma_{\mathrm{e}}$ denotes the electrolyte conductivity, $f$ is the activity coefficient for the salt, $t_{+}$is the transport number for $\mathrm{Li}^{+}, i_{\text {sum }}$ is the sum of all electrochemical current sources, and $Q_{e}$ denotes an arbitrary electrolyte current source. In the mass balance for the salt, $\varepsilon_{\mathrm{e}}$ denotes the electrolyte volume fraction, $D_{\mathrm{e}}$ is the electrolyte salt diffusivity, and $R_{\mathrm{e}}$ the total $\mathrm{Li}^{+}$source term in the electrolyte.

In the electrode, the current density, $i_{s}$ is defined as 


$$
i_{\mathrm{s}}=-\sigma_{\mathrm{s}} \nabla \phi_{\mathrm{s}}
$$

where $\sigma_{\mathrm{s}}$ is electrical conductivity. The domain equation for the electrode is the conservation of current expressed as

$$
\nabla i_{\mathrm{s}}=-i_{\text {sum }}+Q_{\mathrm{s}}
$$

where $Q_{s}$ is an arbitrary current source term. The electrochemical reactions in the physics interface are assumed to be insertion reactions occurring at the surface of small solid spherical particles of radius $r_{\mathrm{p}}$ in the electrodes.

The insertion reaction is described as:

During charging, at anode

$\mathrm{xLi}^{+}+\mathrm{xe}^{-}+$graphite $\rightarrow \mathrm{Li}_{x} \mathrm{C}_{6}$

at cathode

$\mathrm{Li}_{x} \mathrm{Ni}_{0.8} \mathrm{Co}_{0.15} \mathrm{Al}_{0.05} \mathrm{O}_{2} \rightarrow \mathrm{xi}^{+}+\mathrm{xe}^{-}+\mathrm{Ni}_{0.8} \mathrm{Co}_{0.15} \mathrm{Al}_{0.05} \mathrm{O}_{2}$

During discharging, at Anode

$\mathrm{Li}_{x} \mathrm{C}_{6} \rightarrow \mathrm{xLi}^{+}+\mathrm{xe}^{-}+$graphite

at cathode

$\mathrm{xLi}^{+}+\mathrm{xe}^{-}+\mathrm{Ni}_{0.8} \mathrm{Co}_{0.15} \mathrm{Al}_{0.05} \mathrm{O}_{2} \rightarrow \mathrm{Li}_{x} \mathrm{Ni}_{0.8} \mathrm{Co}_{0.15} \mathrm{Al}_{0.05} \mathrm{O}_{2}$

An important parameter for lithium insertion electrodes is the state-of-charge variable for the solid particles, denoted SOC. This is defined as

$$
\mathrm{SOC}=\frac{c_{\mathrm{Li}}}{c_{\mathrm{Li}, \max }}
$$

The equilibrium potentials $E_{0}$ of lithium insertion electrode reactions are typically functions of SOC. The electrode reaction occurs on the particle surface and lithium diffuses to and from the surface in the particles. The mass balance of $\mathrm{Li}$ in the particles is described as

$$
\frac{\partial c_{\mathrm{Li}}}{\partial t}=\nabla\left(D_{\mathrm{s}} \nabla c_{\mathrm{Li}}\right)
$$

where $c_{\mathrm{Li}}$ is the concentration of $\mathrm{Li}$ in the electrode. This equation is solved locally by this physics interface in a 1D pseudo dimension, with the solid phase concentrations at the nodal points for the element discretization of the particle as the independent variable. The gradient is calculated in Cartesian, cylindrical, or spherical coordinates, depending on if the particles are assumed to be best described as flakes, rods or spheres, respectively.

The boundary conditions are as follows:

$$
\begin{aligned}
& \left.\frac{\partial c_{\mathrm{Li}}}{\partial r}\right|_{r=0}=0 \\
& -\left.D_{\mathrm{s}} \frac{\partial c_{\mathrm{Li}}}{\partial r}\right|_{r=r_{p}}=-\left.\mathrm{R}_{\mathrm{Li}}\right|_{r=r_{p}}
\end{aligned}
$$

where $R_{\mathrm{Li}}$ denotes the molar flux of lithium at the particle surface caused by the electrochemical insertion reactions. In the porous electrodes, $i_{\text {sum }}$ denotes the sum of all charge transfers current density contributions according to:

$$
i_{\text {sum }}=\Sigma A_{\mathrm{v}} i_{\text {loc }}
$$

where, $A_{v}$ denotes the specific surface area at any node of the lithium-ion battery interface. Active specific surface area $\left(\mathrm{m}^{2} / \mathrm{m}^{3}\right)$ defines the area of an electrode-electrolyte interface that is catalytically active for porous electrode reactions. Equation 13 describing the total current source 
in the domain is a function of active specific surface area and local current in the electrode. The source term in the mass balance is calculated from:

$$
R_{\mathrm{l}}=-\sum A_{\mathrm{v}} \frac{v_{\mathrm{Li}} i_{\text {loc }}}{n F}+R_{\mathrm{l}, \mathrm{src}}
$$

where $R_{\text {I.src }}$ is an additional reaction source that contributes to the total species source.

At the surface of the solid particles, the following equation is applied:

$$
R_{\mathrm{Li}}=-\sum \frac{A_{\mathrm{v}}}{\frac{S_{\text {shape }} \varepsilon_{\mathrm{s}}}{r_{\mathrm{p}}}} \frac{v_{\mathrm{Li}} i_{\text {loc }}}{n F}
$$

where $\mathrm{n}$ is the number of electrons and $S_{\text {shape }}$ (normally equal to 1 ) is a scaling factor accounting for differences between the surface area $\left(A_{v}\right)$ used to calculate the volumetric current density and the surface area of the particles in the solid lithium diffusion model. $S_{\text {shape }}$ is 1 for Cartesian, 2 for cylindrical, 3 for spherical coordinates and $v_{\mathrm{Li}}$ is the stoichiometric coefficient.

A resistive film (also called solid-electrolyte interface, SEI) might form on the solid particles resulting in additional potential losses in the electrodes. To model a film resistance, an extra solution variable for the potential variation over the film is introduced in the physics interface. The governing equation is then according to

$$
\nabla \phi \phi_{\text {SEI }}=R_{\text {SEI }} \text { sum }_{\text {Sum }}
$$

where $R_{\text {SEI }}$ denotes generalized film resistance, which can be expressed by:

$$
R_{\mathrm{SEI}}=\frac{\delta_{0}+\Delta \delta}{\sigma_{\mathrm{SEl}}}
$$

where, $\delta_{0}$ is initial film thickness, $\Delta \delta$ is film thickness change and $\sigma_{S E I}$ is film conductivity. The activation overpotentials, $\eta$, for all electrode reactions in the electrode then receives an extra potential contribution, which yields

$$
\eta=\phi_{\mathrm{s}}-\phi_{\mathrm{e}}-\phi_{\mathrm{SEl}}-E_{\mathrm{eq}}
$$

where, $E_{\text {eq }}$ is the equilibrium potential of a cell. The battery cell capacity, $Q_{\text {cell,o }}$ is equal to the sum of the charge of cyclable species in the positive and negative electrodes and additional porous electrode material if present in the model [20].

$$
Q_{\text {cell, } 0}=Q_{\text {cycle,pos }}+Q_{\text {cycle, neg }}+Q_{\text {cycl,addm }}
$$

Butler-Volmer equation is used to calculate the local current density in the electrode.

$$
\begin{aligned}
& i_{\text {loc }}=i_{0}\left(\exp \left(\frac{\alpha_{\mathrm{a}} F \eta}{R T}\right)-\exp \left(\frac{-\alpha_{\mathrm{c}} F \eta}{R T}\right)\right) \\
& i_{0}=F k_{\mathrm{c}}{ }^{\alpha^{\alpha}} k_{\mathrm{a}}{ }^{\alpha_{\mathrm{c}}}\left(c_{\mathrm{L}, \max }-c_{\mathrm{Li}}\right)^{\alpha_{\mathrm{a}}} c_{\mathrm{Li}}{ }^{\alpha_{\mathrm{c}}}\left(\frac{c_{\mathrm{e}}}{c_{\mathrm{e}, \mathrm{eff}}}\right)
\end{aligned}
$$

where $\alpha_{\mathrm{a}}$ and $\alpha_{\mathrm{c}}$ are the anode and cathode transfer coefficient and $k_{\mathrm{a}}$ and $k_{\mathrm{c}}$ are reaction rate constant for anode and cathode.

\section{Numerical methods}

1D model of Li-ion battery consists of 3 geometric regions for analysis: negative electrode, separator and a positive electrode. For numerical analysis of the computational domain, 1D meshing is done for 49,59 and 95 mesh elements. The 1D mathematical model is developed for transient analysis of our computational domain in Comsol 5.3a on viable concerns of Li-ion battery, electrochemical parameters, species transport and current distribution, consisting of the principal 
model assumptions and equations with different initial conditions, boundary conditions and numerical solver strategies for solution.

\section{Results and discussion}

Capacity fading of Li ion battery is studied with the effect of various parameters. A summary of the list of parameters used for simulation is shown in Table 1.

Table 1. List of parameters

\begin{tabular}{ll}
\hline Description & Value \\
\hline Particle radius, $\mu \mathrm{m}$ & $0.5,1,2,2.5$ \\
\hline Reaction rate coefficient, $\mathrm{pmol} \mathrm{m}^{-3} \mathrm{~s}^{-1}$ & $200,20,2$ \\
\hline Initial capacity, $\mathrm{C}^{-2}$ & 55761 \\
\hline $1 \mathrm{C}$ discharge current, $\mathrm{A}$ & 15.767 \\
\hline Thickness of negative electrode, $\mu \mathrm{m}$ & 55 \\
\hline Thickness of separator, $\mu \mathrm{m}$ & 30 \\
\hline Thickness of positive electrode, $\mu \mathrm{m}$ & 55 \\
\hline Cell temperature, ${ }^{\circ} \mathrm{C}$ & 45 \\
\hline Maximum cell voltage, $\mathrm{V}$ & 4.1 \\
\hline Minimum cell voltage, $\mathrm{V}$ & 2.5 \\
\hline Initial electrolyte salt concentration, $\mathrm{mol}^{-3} \mathrm{~m}^{-3}$ & 1200 \\
\hline Constant current (charge and discharge), $\mathrm{A}$ & $15.767,-15.767$ \\
\hline SEI Layer conductivity, $\mathrm{S} \mathrm{m} \mathrm{m}^{-1}$ & $5 \times 10^{-6}$ \\
\hline Initial SEl layer thickness, $\mathrm{nm}$ & 1 \\
\hline Number of cycles & 2000 \\
\hline
\end{tabular}

The battery cycling consists of 3 various stages of charging and discharging, as shown in Figure 2:

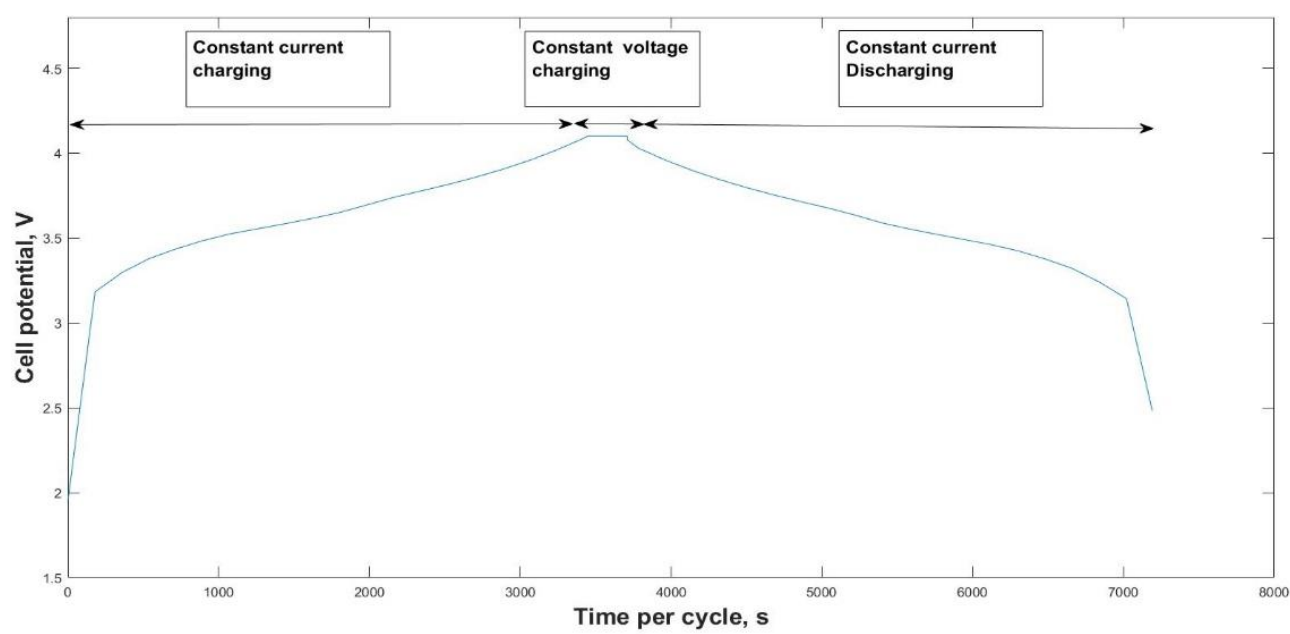

Figure 2. Charge-discharge load cycle

- charging at a constant current rate of $1 \mathrm{C}$ until the cell potential reaches $4.1 \mathrm{~V}$.

- Charging at a constant voltage of $4.1 \mathrm{~V}$.

- Discharging at constant current discharge rate at $1 \mathrm{C}$ until the cell potential reaches the minimum voltage of $2.5 \mathrm{~V}$. 


\section{Effect of particle radius on capacity fading in lithium-ion batteries}

Research on anode particle radius on capacity fading in lithium-ion batteries has been done previously. Rai [21] postulated that batteries with smaller anode particle sizes generate better capacity. The authors postulated that smaller particles(graphite) allow quicker lithium-ion intercalation and deintercalation due to the short distances for lithium-ion transport within the particles. There is no agreed-upon consensus for optimal particle size in lithium-ion batteries though particles less than $150 \mathrm{~nm}$ are mainly used. Wu [22] investigated the effect of silicon particle size in the micrometer range when used as a lithium-ion battery anode. The authors have found out in their study that particle size of $3 \mu \mathrm{m}$ shows better outcomes with respect to the $20 \mu \mathrm{m}$ particle size with an initial capacity of $800 \mathrm{mAh} / \mathrm{g}$ and retention of $600 \mathrm{mAh} / \mathrm{g}$ after 50 cycles. Buqa [23] investigated three different graphite particle sizes $(6,15$ and $44 \mu \mathrm{m})$ and showed that smaller particles could achieve better capacity retention. Several authors like Drezen [24] and Fey [25] have postulated that smaller particles improve capacity retention. Mei has [26] postulated that energy and power density increase with smaller particle sizes due to lower overpotential. Mei [26] has also postulated that smaller particle size increases the surface area for reaction. Our focus was to study the effect of the anode particle radius on the capacity fading in lithium-ion batteries taking into consideration lithium losses during cycling.

Figure 3 shows the capacity fading of a lithium-ion battery with cycling for various anode particle radii. The model assumes zero lithium loss during the process of cycling. Four different anode particle radii $(0.5,1,2$ and $2.5 \mu \mathrm{m})$ were considered for analysis. It is seen that the least capacity fading (high relative capacity) is seen for an anode particle radius of $0.5 \mu \mathrm{m}$. Relative capacity is defined as the capacity of the battery at any point of time divided by the initial capacity of the battery. It can be seen that as the anode particle radius increases from 0.5 to $2.5 \mu \mathrm{m}$, the relative capacity decreases over 2000 cycles.

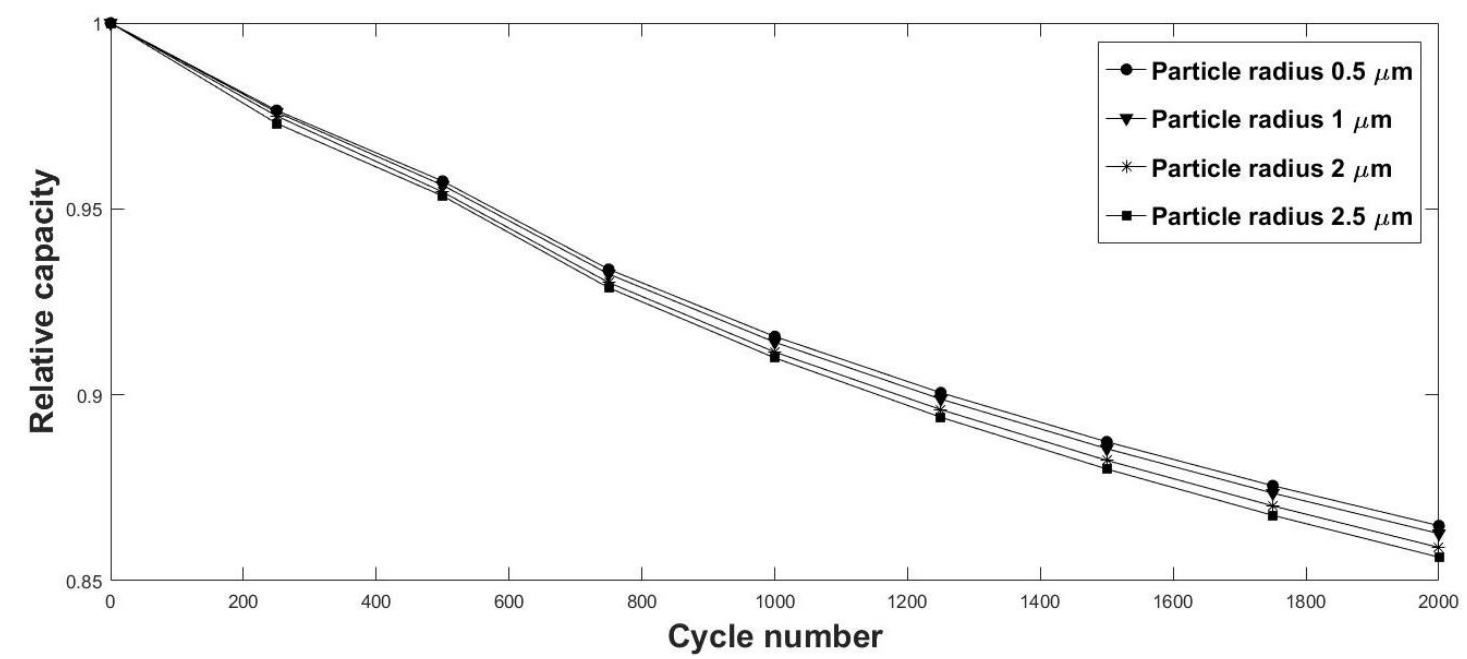

Figure 3. Capacity fading with cycling for various anode particle radius with zero lithium loss

Figure 4 shows the capacity fading in a lithium-ion battery cycling for four different particle radii $(0.5,1,2$ and $2.5 \mu \mathrm{m})$ with 10 percent lithium loss during cycling. During charge-discharge cycling, there is more lithium loss during initial cycles. A comparison of Figures 3 and 4 shows that the capacity loss is seen to be less without cyclable lithium loss compared to $10 \%$ initial lithium loss as the number of cycles increases. This is clearly shown in Figure 5 . It is seen from Figure 5 that there is less capacity loss of around $3 \%$ when we go from zero percent lithium loss to 10 percent lithium loss during cycling. 


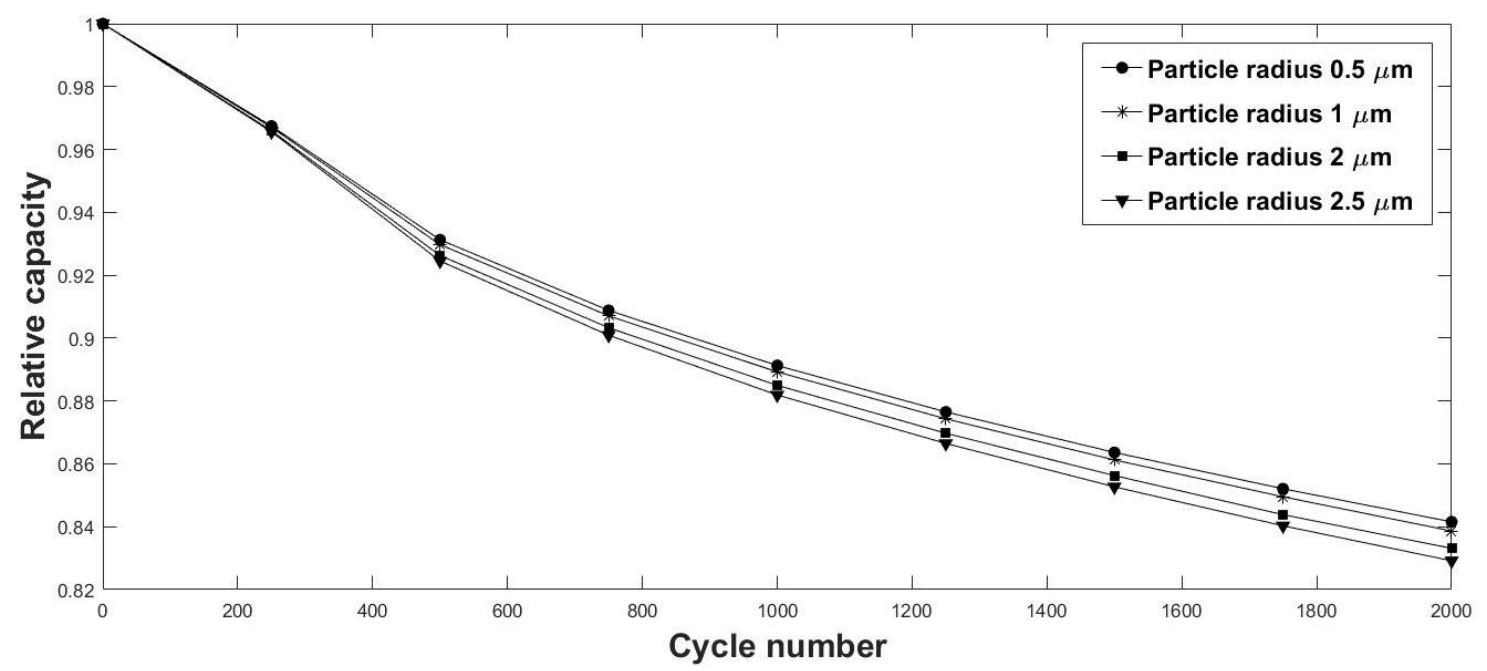

Figure 4. Capacity fading with cycling for various anode particle radius with lithium loss

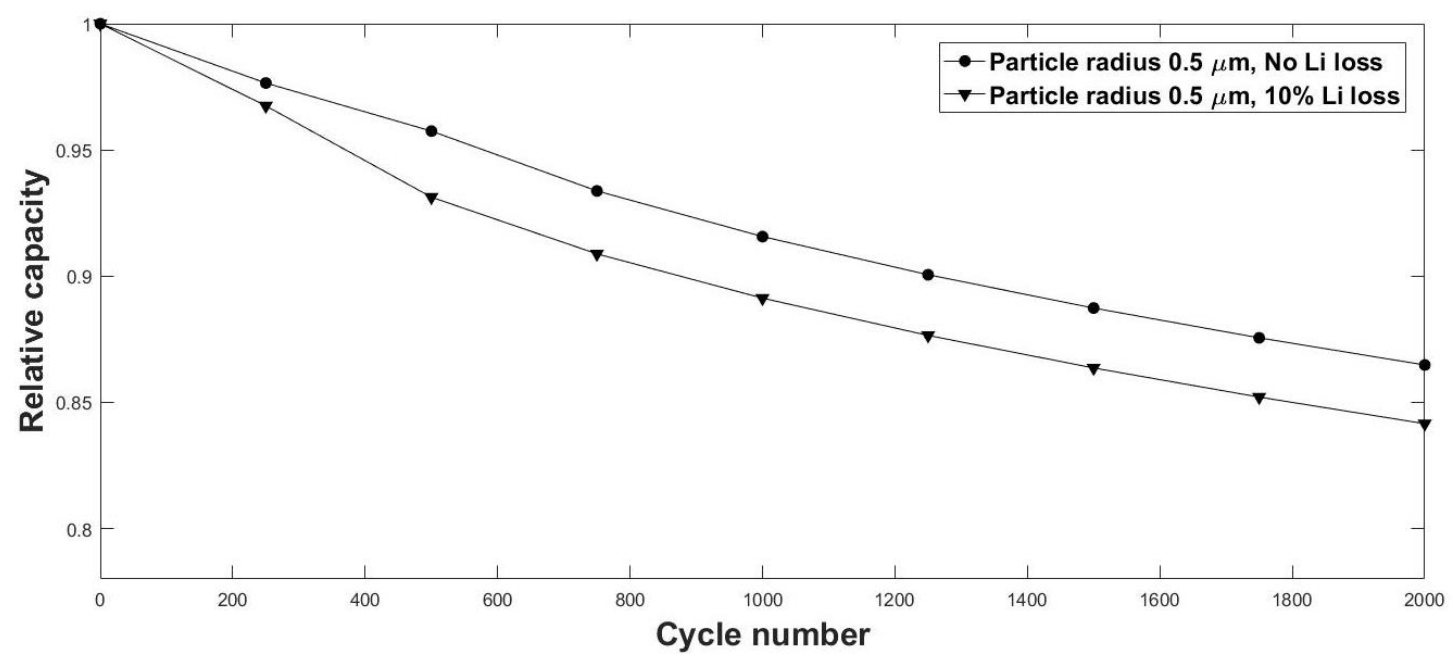

Figure 5. Comparison of relative capacity with and without lithium loss

Figures 6 and 7 show the capacity loss in the battery as a function of the anode reaction rate constant.

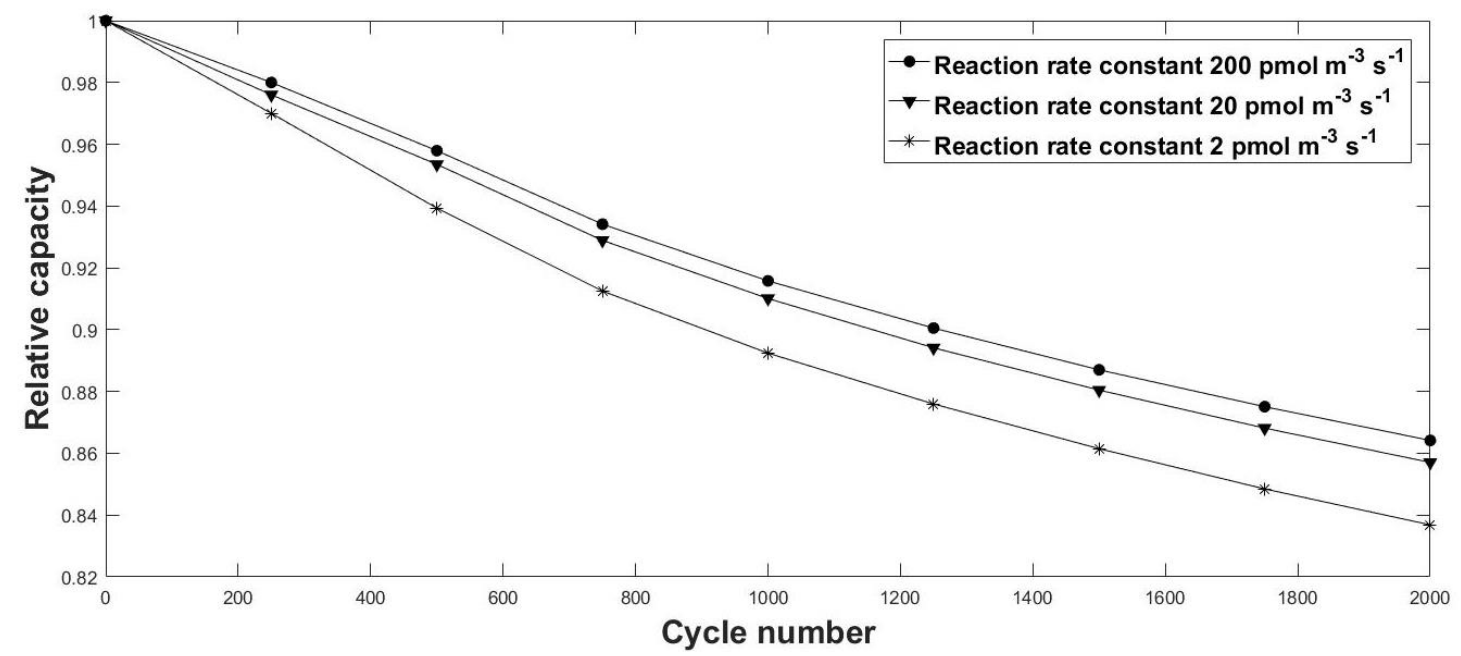

Figure 6. Capacity loss with cycling for various anode reaction rate constant without lithium loss

The anode reaction rate constant indicates the intercalation/deintercalation reaction rate constant. Figure 6 shows that when the intercalation/deintercalation reaction rate constant is the 
highest, the capacity loss is the lowest. With increasing intercalation/deintercalation reaction rate, the rate of lithium transport increases, effectively increasing the capacity of the battery. While Figure 6 shows the capacity loss when there is no initial cyclable lithium loss during cycling, Figure 7 shows the capacity loss when there is $10 \%$ initial lithium loss during cycling.

Figure 8 shows the comparison of the capacity losses when there are 0 and $10 \%$ lithium losses during cycling. The figure shows that when the initial lithium loss during cycling increases from zero percent to 10 percent, there is a $4 \%$ differential in the capacity loss due to side reactions.

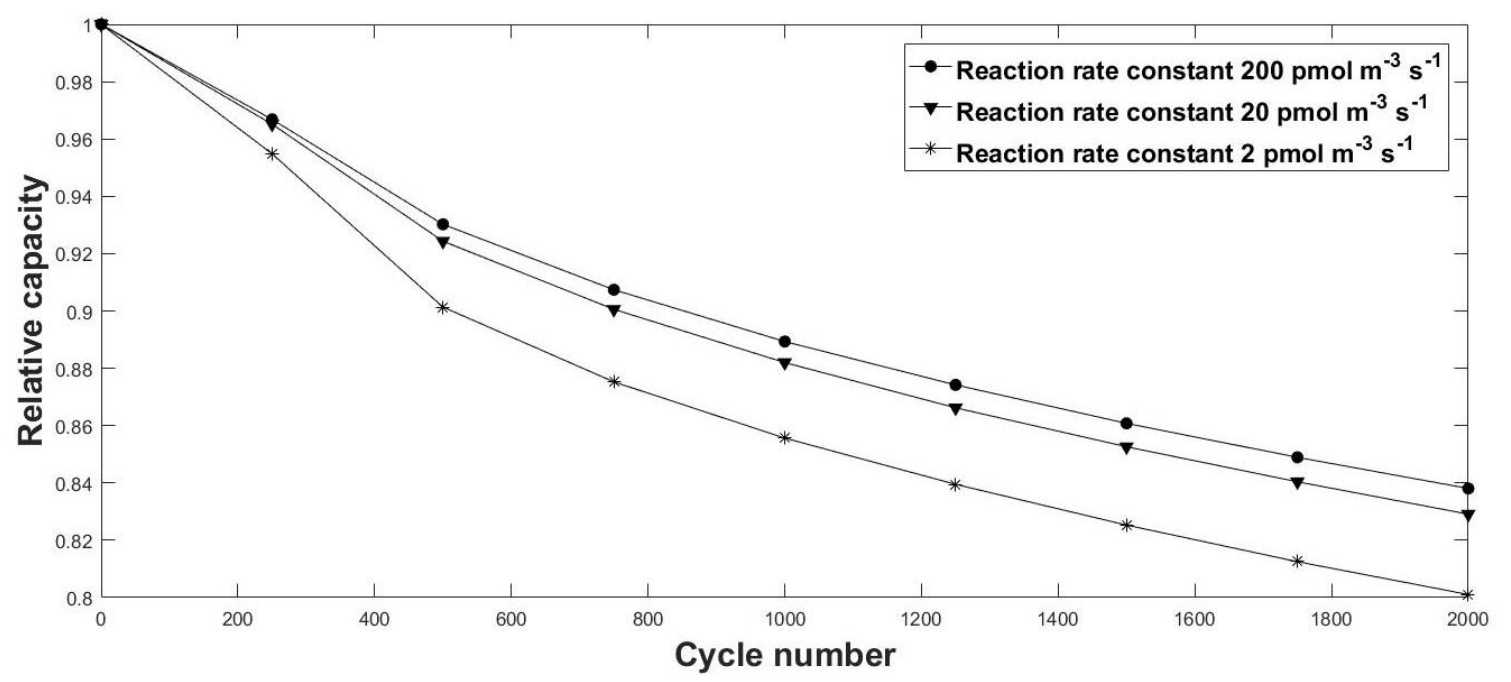

Figure 7. Capacity loss with cycling for various anode reaction rate constants with $10 \%$ Li loss during cycling

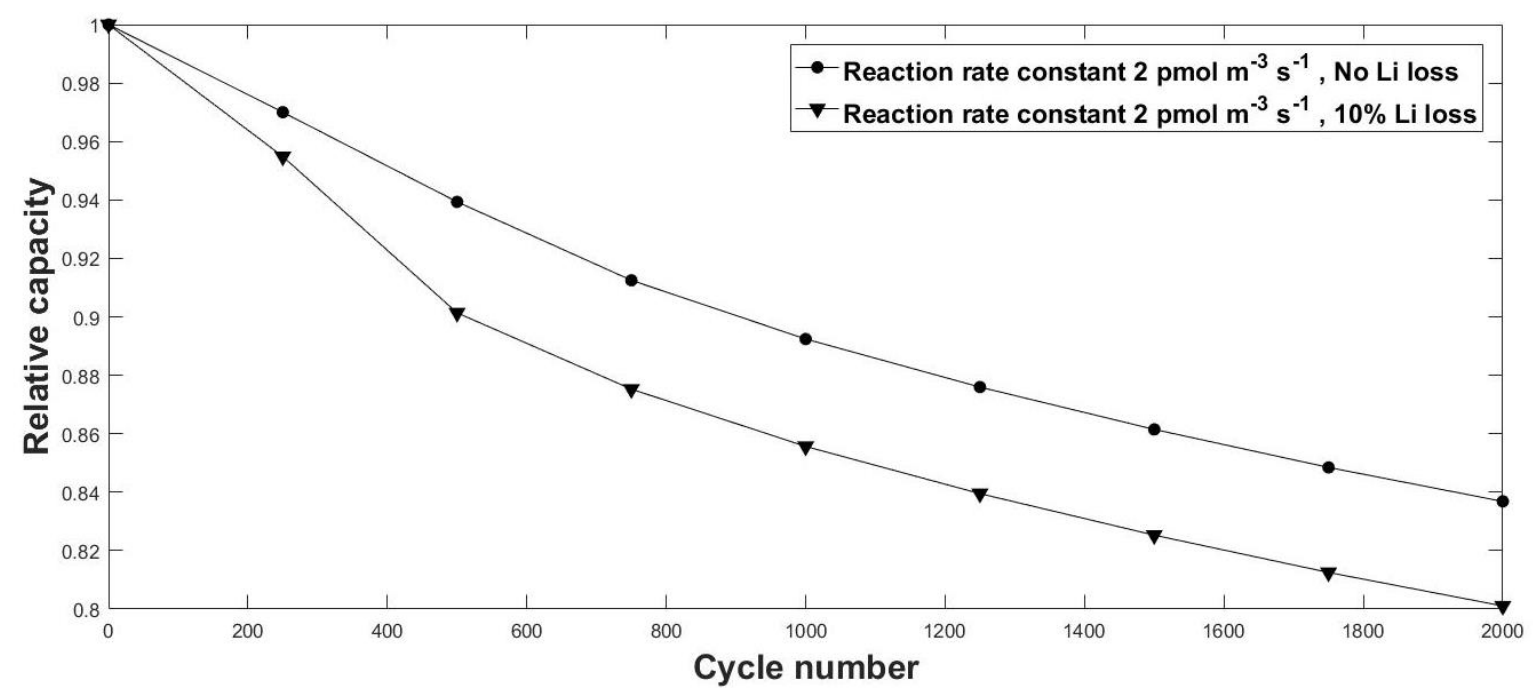

Figure 8. Comparison of capacity loss for $0 \%$ Li loss and $10 \%$ Li loss

Effect of anode radius on lithium-ion concentration at the anode/SEI interphase

Figure 9 shows the concentration of lithium ions at the anode/SEl interphase as a function of anode particle radius (4 different particle radii are shown in the figure). It is seen that the highest concentration of lithium ions at the anode/SEI interphase occurs at the smallest particle radius. Smaller anode particles allow lithium ions to intercalate and deintercalated quickly due to the short diffusion path for lithium ion transport within the particles. This leads to a higher concentration of lithium ions at the anode/SEI interphase.

Figure 10 shows the concentration of lithium ions at the anode/SEI interphase as a function of the reaction rate constant for lithium intercalation. With the increasing rate constant of deintercalation, the concentration of lithium ions at the anode/SEl interphase is seen to increase. 


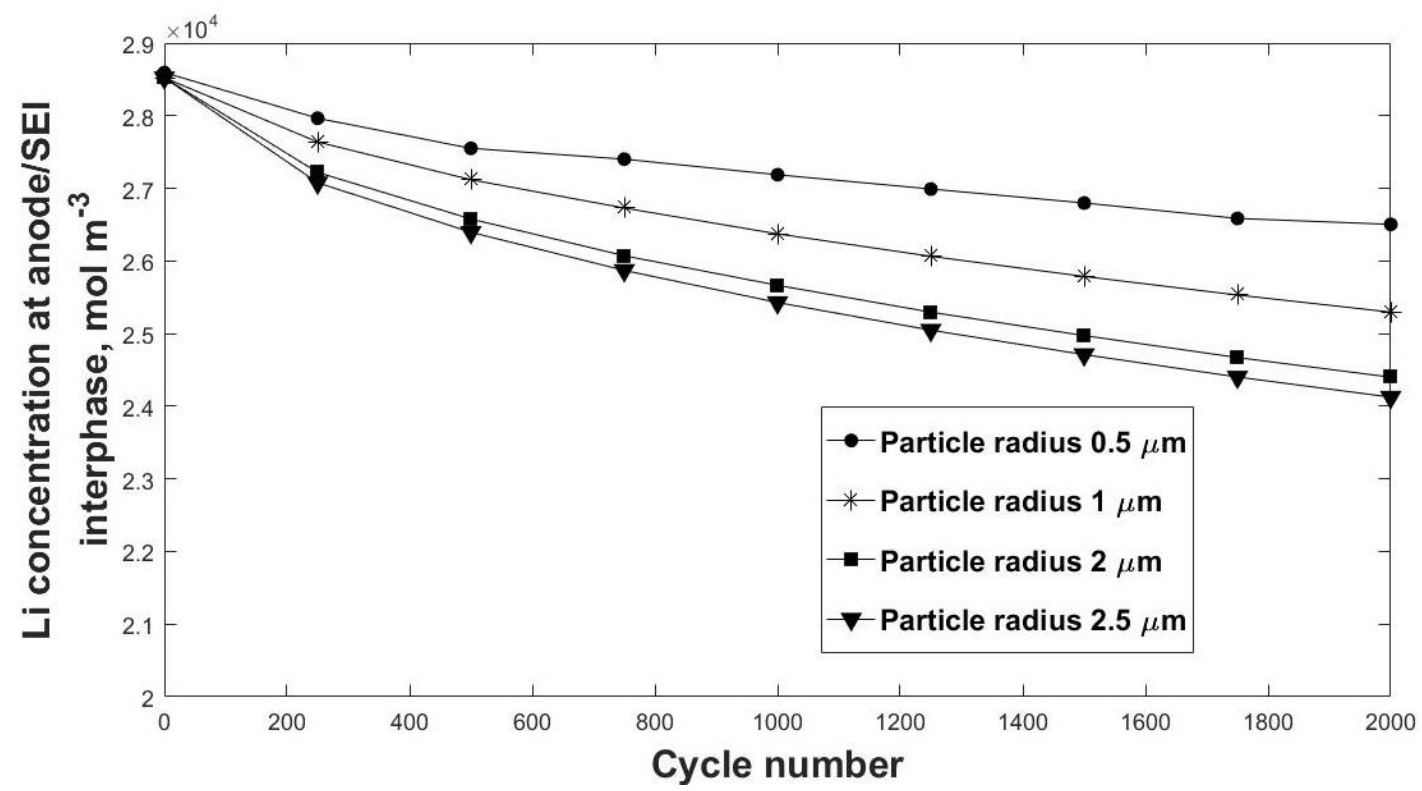

Figure 9. The concentration of lithium ions at the anode/SEI interphase as a function of anode particle radius

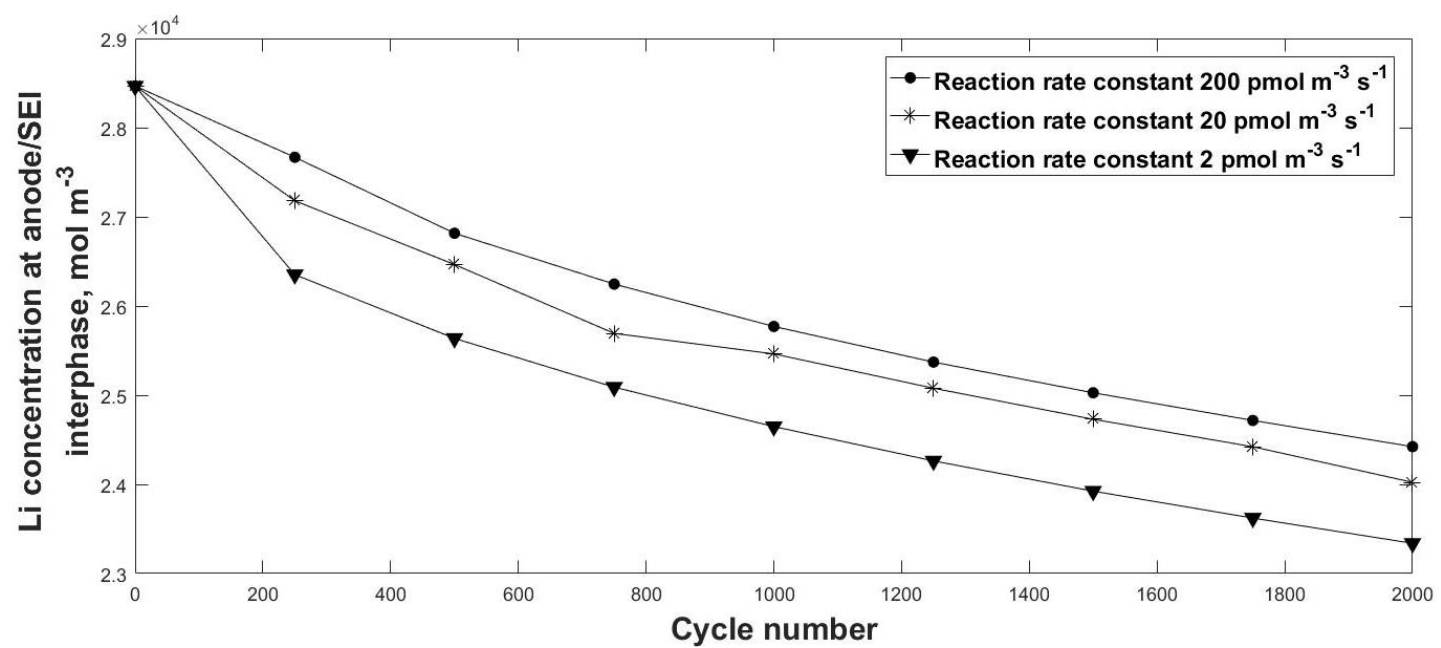

Figure 10. The concentration of lithium ions at the anode/SEI interphase as a function of the anode reaction rate constant

Figure 11 shows the concentration of lithium ions at the anode/SEI interphase varying with anode radius in the first and the $2000^{\text {th }}$ cycle.

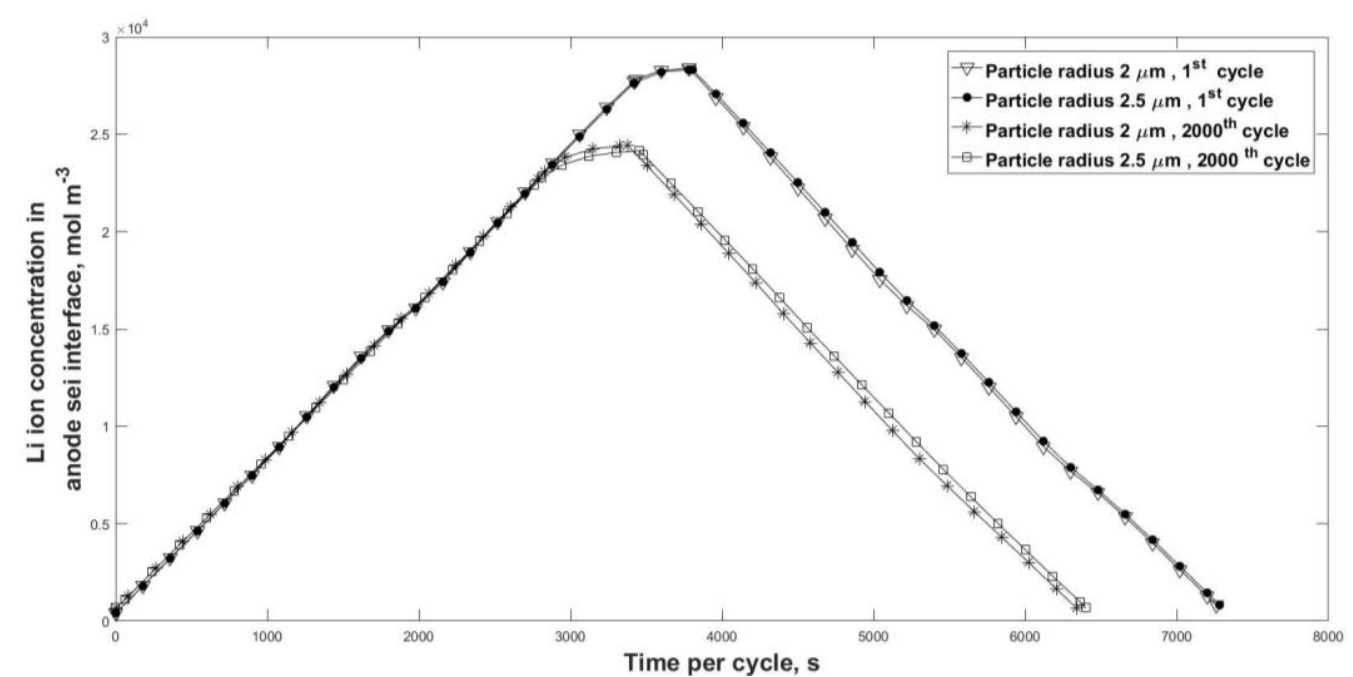

Figure 11. The concentration of lithium ions at the anode/SEI interphase in the first and $2000^{\text {th }}$ cycle 
During the charging cycle, lithium from the cathode moves to the anode and hence the concentration of lithium ions at the anode/SEI interphase increases. The lithium ions move from the anode to the cathode during the discharging cycle. Hence, the concentration of lithium ions at the anode/SEI interphase is seen to go from maximum to zero. As the battery cycles, lithium ions are lost in the intercalation deintercalation process. Hence, the concentration of lithium ions at the anode/SEI interphase is lower in the $2000^{\text {th }}$ cycle than in the $1^{\text {st }}$ cycle.

The potential drop across the SEl layer as a function of anode particle radius

Figure 12 shows the effect of anode particle radius on the potential drop across the SEl layer. The figure analyses the effect of four different particles sizes on the potential drop across the SEl layer. The least potential drop across the SEI layer occurs when the anode particle size is the smallest. As explained earlier, smaller anode particle sizes lead to higher intercalation deintercalation rates leading to higher current densities. Given a constant power output, this indicates a lower potential drop across the cell and hence a lower potential drop across the SEI layer.

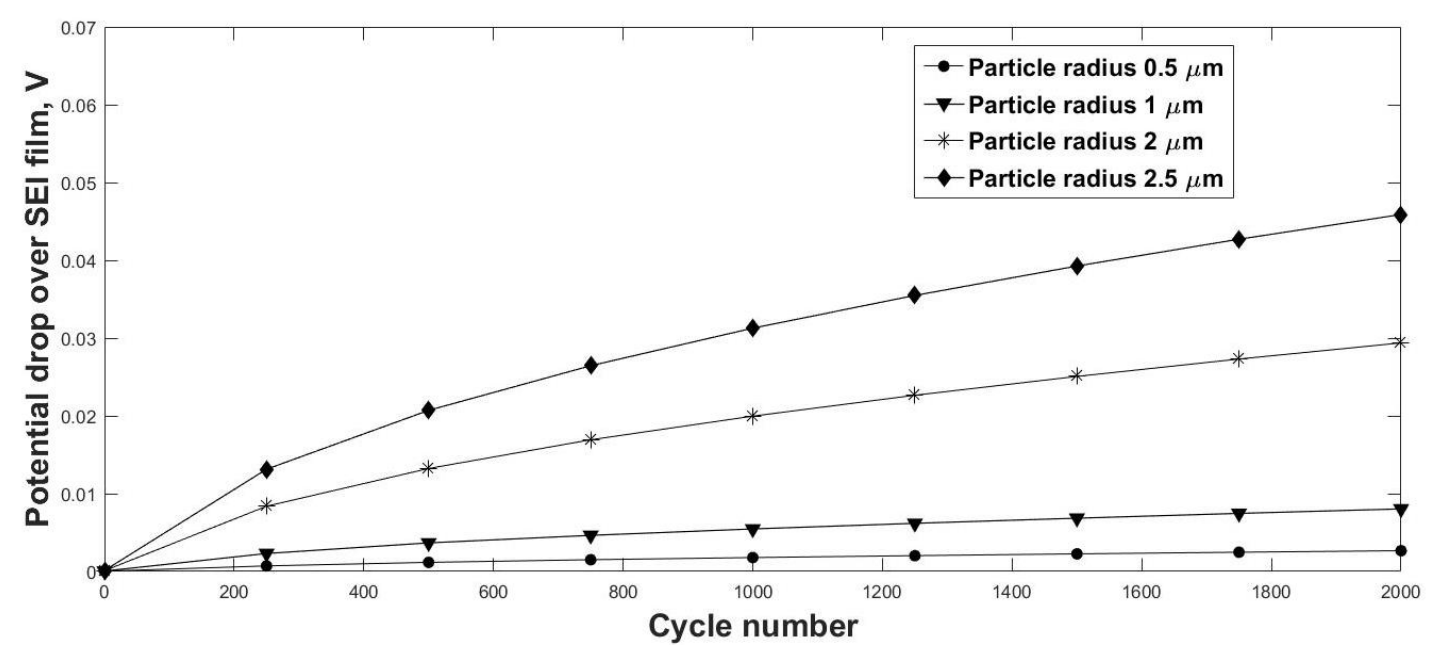

Figure 12. Potential drop over the SEI film with cycle number for various anode particle radius

Figure 13 shows the effect of the anode reaction rate constant on the potential drop across the SEl layer.

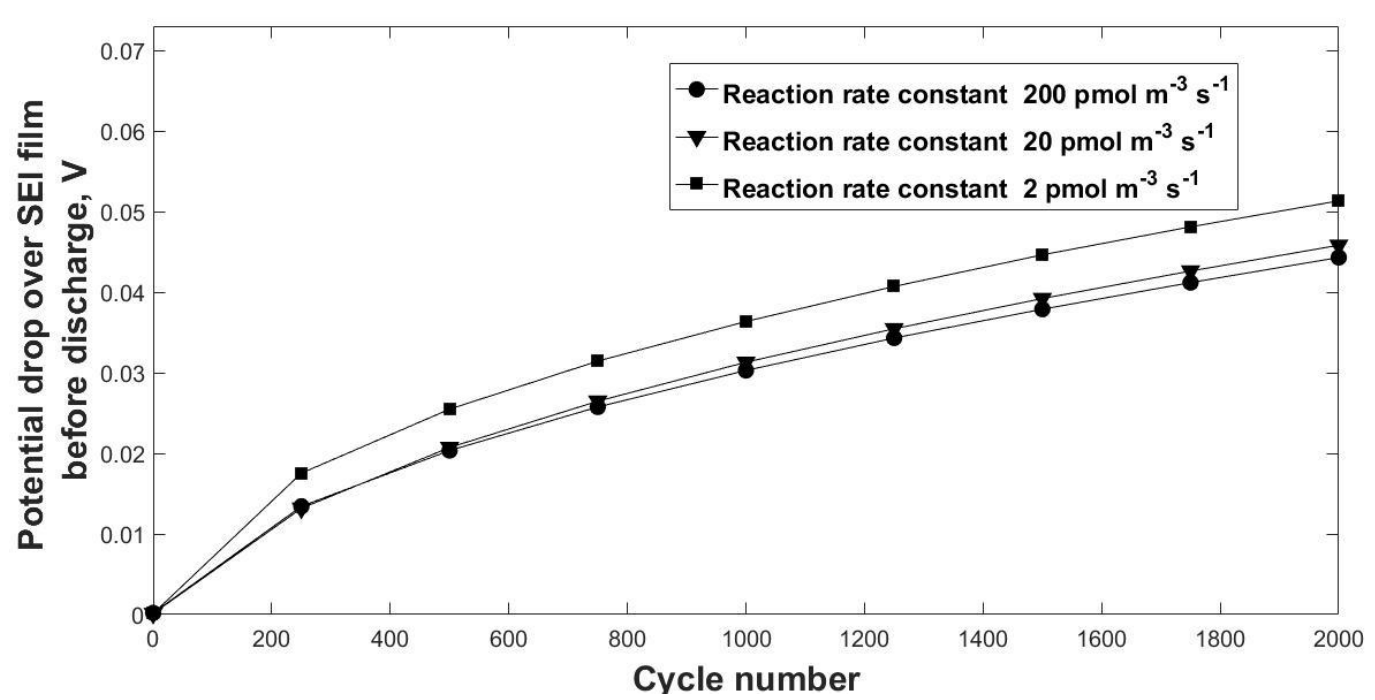

Figure 13. Potential drop over the SEI layer as a function of anode reaction rate constant 
The graph shows that the potential drop across the SEI layer increases with decreasing rate constant. The anode reaction rate constant indicates the rate of intercalation deintercalation of lithium ions in the anode particles. When the anode reaction rate constant is lower, the intercalation/deintercalation of lithium ions in the anode is reduced, giving rise to a lower current density. Given a constant power output, this indicates an increased potential drop across the cell and, hence, a potential drop across the SEl layer. This is shown in Figure 13.

Figure 14 shows the comparison of modelling predictions with experimental data $[3,11]$. Modeling predictions are found to compare well with experimental data. The model comparisons are made for $1 \mathrm{C}$ discharge at $45^{\circ} \mathrm{C}$ operating conditions for the lithium-ion battery cell. The parameters used for data fitting are shown in Table 1.

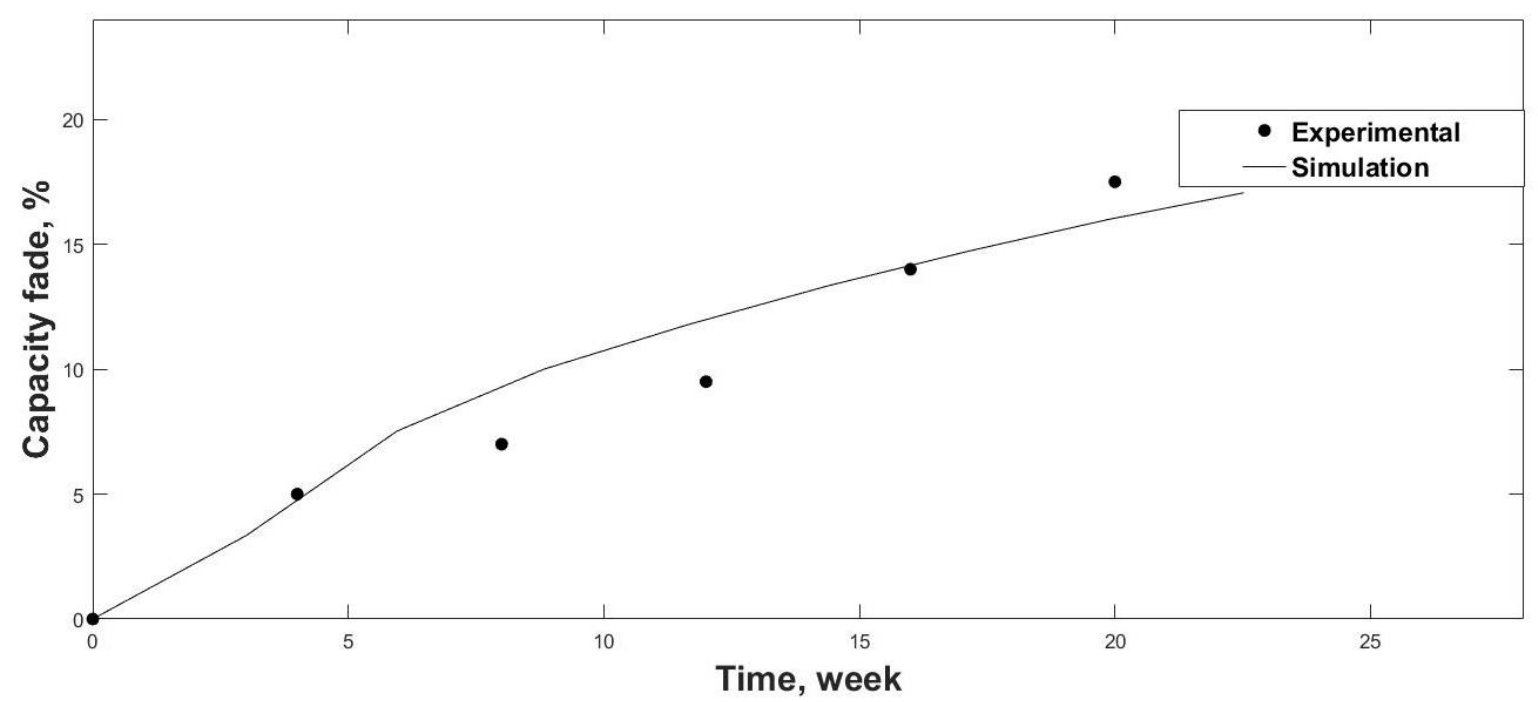

Figure 14. Comparison of modelling predictions with experimental data of capacity fading percentage at $1 C$ discharge rate and $45^{\circ} \mathrm{C}[3,11]$

\section{Conclusion}

A 1-dimensional mathematical model is developed to study the effect of anode particle radius and anode reaction rate constant on capacity fading of a Li-ion battery. Simulation results predict that for the smallest anode particle radius of $0.5 \mu \mathrm{m}$, capacity fading is less in comparison to $2.5 \mu \mathrm{m}$. Smaller anode particle radii lead to faster lithium intercalation/deintercalation rates leading to higher current densities and lesser capacity fade. Smaller anode particle radii also lead to increasing anode surface area for reaction. The anode reaction rate constants are also found to play a major role in the capacity fading of lithium-ion batteries. It is found that the higher the anode reaction rate constant, the lesser is the capacity fade in the battery. Model results are compared with experimental data and found to compare well.

\section{Nomenclature}

$\begin{array}{ll}\phi_{\mathrm{s}} & \text { The electric potential at electrode } \\ \phi_{\mathrm{e}} & \text { Electrolyte potential } \\ \Delta \phi_{\mathrm{SEi}} & \text { The potential losses due to SEI layer } \\ C_{\mathrm{Li}} & \text { Concentration of lithium in the electrode particles } \\ C_{\mathrm{e}} & \text { Electrolyte salt concentration } \\ \sigma_{\mathrm{e}} & \text { Electrolyte conductivity } \\ \mathrm{F} & \text { Activity coefficient for the salt }\end{array}$




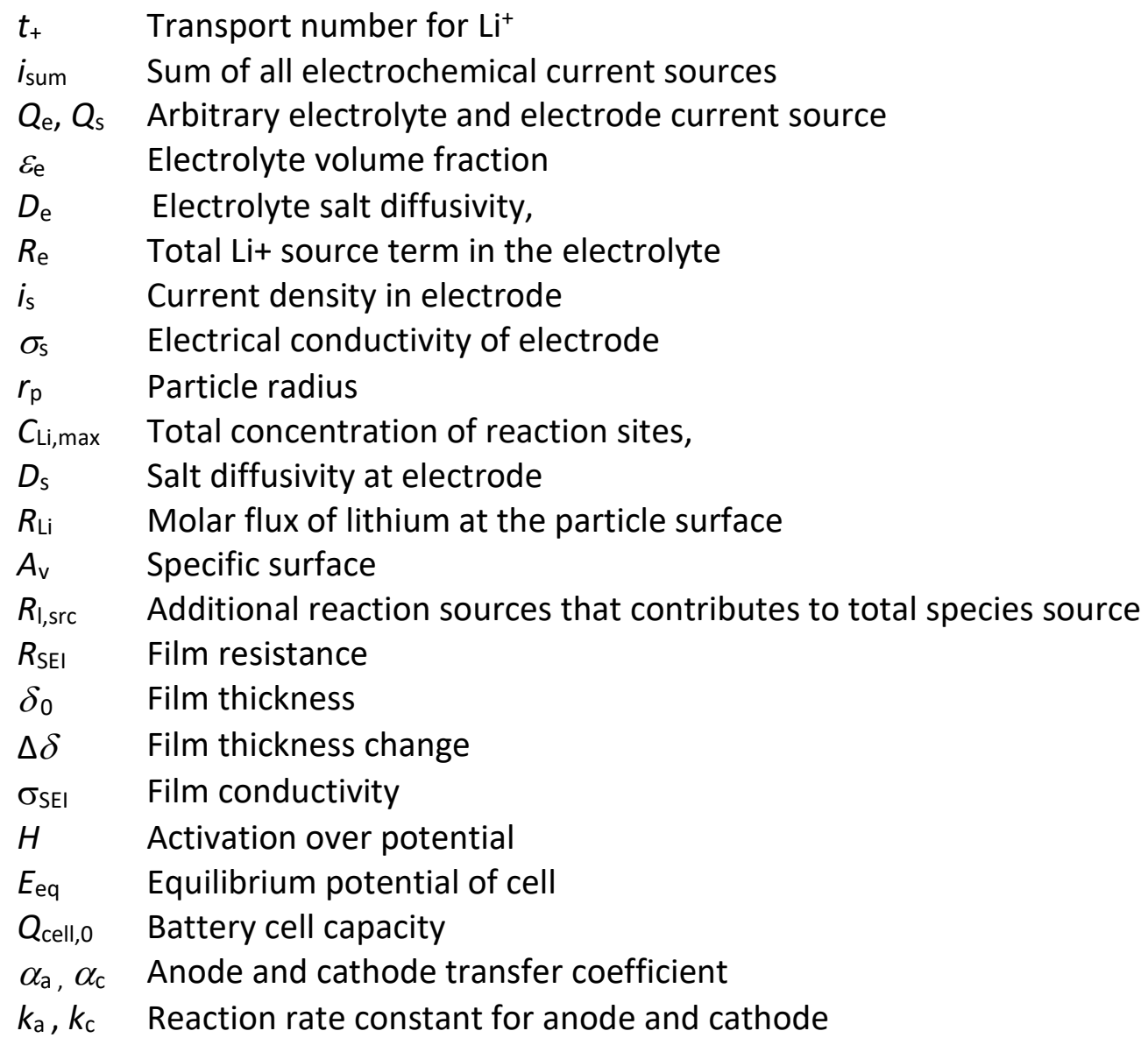

Acknowledgement: The authors would like to acknowledge BITS Pilani, Hyderabad and Council for Scientific and Industrial Research, CSIR Grant No: (No:22/0784/19/EMR II), which helped us in publishing this article.

Data availability statement: Data used for this paper can be provided on request

\section{References}

[1] B. S. Haran, P. Ramadass, R. E. White, B. N. Popov, Seventeenth Annual Battery Conference on Applications and Advances, Proceedings of Conference (Cat. No. 02TH8576), Long Beach, CA, USA, 2002, 13-18. https://doi.org/10.1109/BCAA.2002.986361.

[2] X. Han, M. Ouyang, L. Lu, J. Li, Energies 7(8) (2014) 4895-4909. https://doi.org/10.3390/en7084895

[3] B. Y. Liaw, E. P. Roth, R. G. Jungst, G. Nagasubramanian, H. L. Case, D. H. Doughty, Journal of Power Sources 119-121 (2003) 874-886. https://doi.org/10.1016/S0378-7753(03)00196-4.

[4] V. Ramadesigan, K. Chen, N. A. Burns, V. Boovaragavan, R. D. Braatz, V. R., Journal of the Electrochemical Society 158 (2011) A1048. https://doi.org/10.1149/1.3609926.

[5] A. M. Colclasure, K. A. Smith, R. J. Kee, Electrochimica Acta 58 (2011) 33-43. https://doi.org/10.1016/i.electacta.2011.08.067.

[6] M. B. Pinson, M. Z. Bazant, Journal of the Electrochemical Society 160 (2013) A243-A250. https://doi.org/10.1149/2.044302jes.

[7] B. Ziv, V. Borgel, D. Aurbach, J.-H. Kim, X. Xiao, B.R. Powell, Journal of the Electrochemical Society 161 (2014) A1672-A1680. https://doi.org/10.1149/2.0731410jes.

[8] L. Liu, J. Park, X. Lin, A.M. Sastry, W. Lu, Journal of Power Sources 268 (2014) 482-490. https://doi.org/10.1016/i.jpowsour.2014.06.050.

[9] J. Guo, Z. Li, T. Keyser, Y. Deng, Proceedings of the 2014 Industrial and Systems Engineering Research Conference, Montréal, Canada (2014) 913-919. 
[10] S. Ramesh, B. Krishnamurthy, Journal of the Electrochemical Society 162 (2015) A545-A552. https://doi.org/10.1149/2.0221504jes.

[11] S. Ramesh, K.V. Ratnam, B. Krishnamurthy, International Journal of Electrochemistry 2015 (2015) 1-9. https://doi.org/10.1155/2015/439015

[12] J. Xu, R. D. Deshpande, J. Pan, Y.-T. Cheng, V. S. Battaglia, Journal of the Electrochemical Society 162 (2015) A2026-A2035. https://doi.org/10.1149/2.0291510jes

[13] A. H. N. Shirazi, M. R. Azadi Kakavand, T. Rabczuk, Journal of Nanotechnology in Engineering and Medicine 6(4) (2015) 041003. https://doi.org/10.1115/1.4032012

[14] R. Singhvi, R. Nagpal, B. Krishnamurthy, Journal of the Electrochemical Society 163 (2016) A1214-A1218. https://doi.org/10.1149/2.0601607jes.

[15] J. Liang Cheng, X. Hai LI, Z. Xing Wang, H. Jun Guo, Transactions of Nonferrous Metals Society of China 27 (2017) 1602-1607. https://doi.org/10.1016/S1003-6326(17)60182-1.

[16] A. Tomaszewska, Z. Chu, X. Feng, S. O’Kane, X. Liu, J. Chen, C. Ji, E. Endler, R. Li, L. Liu, Y. Li, S. Zheng, S. Vetterlein, M. Gao, J. Du, M. Parkes, M. Ouyang, M. Marinescu, G. Offer, B. Wu, eTransportation 1 (2019) 100011. https://doi.org/10.1016/i.etran.2019.100011

[17] S. Gantenbein, M. Schönleber, M. Weiss, E. Ivers-Tiffée, Sustainability 11(23) (2019) 6697. https://doi.org/10.3390/su11236697

[18] D. Lee, B. Koo, C. B. Shin, S. Y. Lee, J. Song, I. C. Jang, J. J. Woo, Energies 12(22) (2019) 4386. https://doi.org/10.3390/en12224386

[19] S. Khaleghi Rahimian, M. M. Forouzan, S. Han, Y. Tang, Electrochimica Acta 348 (2020) 136343. https://doi.org/10.1016/j.electacta.2020.136343

[20] C. Inc., Batteries \& Fuel Cells Module User's Guide, COMSOL Multiphysics Help (2012).

[21] A. K. Rai, B. J. Paul, J. Kim, Electrochimica Acta 90 (2013) 112-118. https://doi.org/10.1016/i.electacta.2012.11.104

[22] H. Wu, G. Chan, J.W. Choi, I. Ryu, Y. Yao, M.T. Mcdowell, S.W. Lee, A. Jackson, Y. Yang, L. Hu, Y. Cui, Nature Nanotechnology 7(5) (2012) 310-315. https://doi.org/10.1038/nnano.2012.35

[23] H. Buqa, D. Goers, M. Holzapfel, M. E. Spahr, P. Novak, Journal of the Electrochemical Society 152(2) (2005) A474-A481. https://doi.org/10.1149/1.1851055

[24] T. Drezen, H. E. Kwon, P. Bowen, I. Teerlinck, M. Isono, I. Exnar, Journal of Power Sources 174 (2007) 949-953 https://doi.org/10.1016/j.jpowsour.2007.06.203

[25] G. T. K. Fey, Y. G. Chen, H. M. Kao, Journal of Power Sources 189 (2009) 169-178. https://doi.org/10.1016/i.jpowsour.2008.10.016

[26] W. Mei, H. Chen, J. Sun, Q.Wang, Sustainable Energy and Fuels 3 (2019) 148-165 https://doi.org/10.1039/C8SE00503F

(C2021 by the authors; licensee IAPC, Zagreb, Croatia. This article is an open-access article distributed under the terms and conditions of the Creative Commons Attribution license (https://creativecommons.org/licenses/by/4.0/) 